\title{
Numerical Characteristics of Friction Stir Spot Welds
}

\author{
Honggang Yang ${ }^{1, a}$, Haijun Yang ${ }^{2, b}$ and Xin Zhao ${ }^{3, c}$ \\ ${ }^{1}$ School of Automotive, Shanghai Dianji University, Shanghai, 201306, China \\ ${ }^{2}$ School of Automotive, Shanghai Dianji University, Shanghai, 201306, China \\ ${ }^{3}$ Shanghai Aerospace Science and Technology Corporation, Shanghai, 200245, China \\ aemail: yanghg@sdju.edu.cn, bemail: yanghj@sdju.edu.cn, cemail: soarfalcon@hotmail.com
}

Keywords: Mechanical Property; Friction Stir Spot Welding; Tensile Shear Load

\begin{abstract}
As a solid state joining process, friction stir spot welding (FSSW) has a strong potential to be applied in the aerospace and automotive industries. Mechanical property of the FSSW joint takes important influence on connection performance. In the present paper, numerical simulation model of mechanical property of the friction stir spot welds is established, based on the study of the microstructure of the joint. Stress distribution and deformation under tensile shear loads was obtained, and the failure mechanism is investigated. Research results can provide guidance for welding quality improvement of the FSSW joints.
\end{abstract}

\section{Introduction}

With the promotion of weight reduction in modern automobile industry, aluminum alloys have been widely applied in the vehicle structure and design. As a solid state joining process, friction stir spot welding (FSSW) has already been used for construction of aluminum components in the automotive industries. Compared with conventional resistance spot welding, FSSW offers many advantages, such as low heat distortion, low energy consumption, excellent mechanical properties and a simple production procedure [1].

During FSSW process, tool geometry, tool penetration, rotating speed and the dwell time essentially determine the heat generation, material flow, weld geometry and the mechanical properties of the weld joint. Therefore, in order to improve welding quality, many experiments and numerical simulation models are conducted to investigate welding mechanism and to calculate optimum welding conditions. Badarinarayan $\mathrm{H}$. studied the effect of pin shape and pin length on the static strength of the friction stir spot welded coupons. Four different pin shapes were evaluated and three different pin lengths were considered for each pin shape [2]. Merzoug M. centered the tests on the description of the significant parameters of process FSSW. The shape of the tool and the welding parameters were found to have a great influence on the mechanical properties of the joint of welding [3]. Sato Y. S. examined interfacial microstructures and lap shear strengths of friction stir spot welds of aluminum alloy and magnesium alloy [4].

The use of numerical approach for the structural analysis of FSSW is also widely used. Joint strength is mainly analyzed under a technological point of view, in order to define a production optimum. Dongun Kim [5] performed thermo-mechanical simulations of the FSSW process to understand the effect of pin geometry on weld strength and material flow, utilizing Lagrangian and Eulerian formulations, respectively. Hirasawa S. [6] analyzed temperature distribution and plastic deformation flow during the FSSW process with the fluid flow model and the elastic-plastic deformation model using the particle method.

In the present paper, according to the microstructure of welds, the numerical simulation model of FSSW joints was established using ANSYS software. The mechanical properties and deformation behavior were analyzed, and the stress distribution under tensile shear loads was obtained. 


\section{Microstructure of FSSW Joints}

Figure 1 shows the microstructure of FSSW joints of aluminum alloy 6061-T6 with thickness 2.0mm. Four different zones can be distinguished, stir zone (SZ), thermal mechanical affected zone (TMAZ), heat affected zone (HAZ) and base material (BM). Stir zone, the innermost zone located all around the blind hole generated by tool pin, presents a complete re-crystallization. As you move along the radius direction towards external radius, TMAZ occurs, where the material has been modified mechanically by the tool and thermically by the generated heat when the friction between metal and tool occurs. Beyond this zone, the material is subjected exclusively to the effects of heat dissipated during the welding process, which is called HAZ. The outer material beyond this zone, known as BM, is considered not modified by the welding process, which represents material that shows no modification in properties.

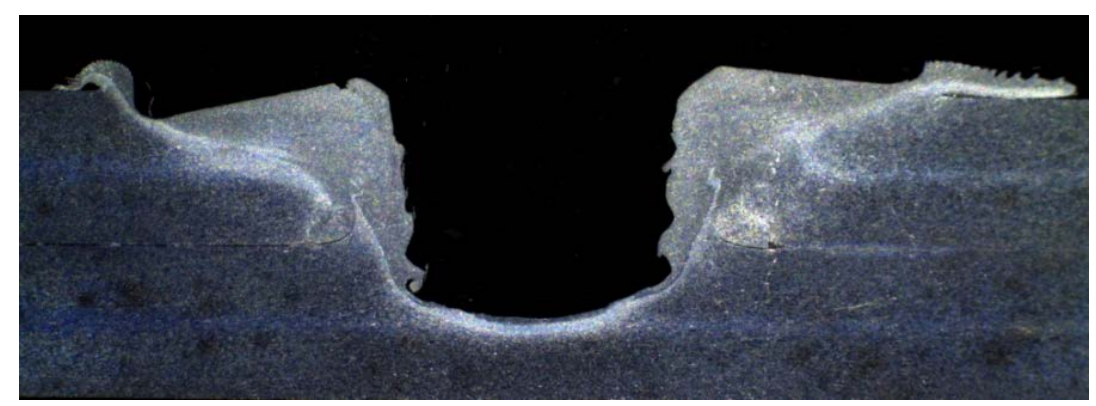

Fig.1. Microstructure of FSSW joints

\section{Numerical Simulation Model}

In order to realize a tool that allows to investigate the mechanical behavior of a FSSW joint in the case of tensile shear loads, it is necessary to define a detailed parametric numerical model. Finite element analysis was conducted to study the mechanical properties of friction stir spot welds, and the finite element model was generated using the ANSYS program.

Because of the different structure, material properties are different in the SZ, TMAZ, HAZ and BM. Correlations between hardness and tensile properties have been proposed by Zhou et al[7]. Therefore, in order to improve the precision of the simulation, the same relationships between the hardness and tensile properties of aluminum alloy, including the ultimate tensile strength, $\sigma_{u t s}$ and yield strength, $\sigma_{y}$ were assumed for the simulation:

$$
\begin{gathered}
\sigma_{\text {uts }}=\sigma_{0}+\mathrm{k} * \mathrm{H}_{\mathrm{v}} \\
\sigma_{\mathrm{y}}=\mathrm{k} * \mathrm{H}_{\mathrm{v}}
\end{gathered}
$$

where $\sigma_{0}$ and $k$ are constants, and $H_{v}$ is Vickers hardness. According to the microstructure of FSSW joints, considering all the dimensions and properties variables, the numerical simulation model was established, as shown in Fig. 2. Because of the symmetrical structure, only half of the specimen was modeled.

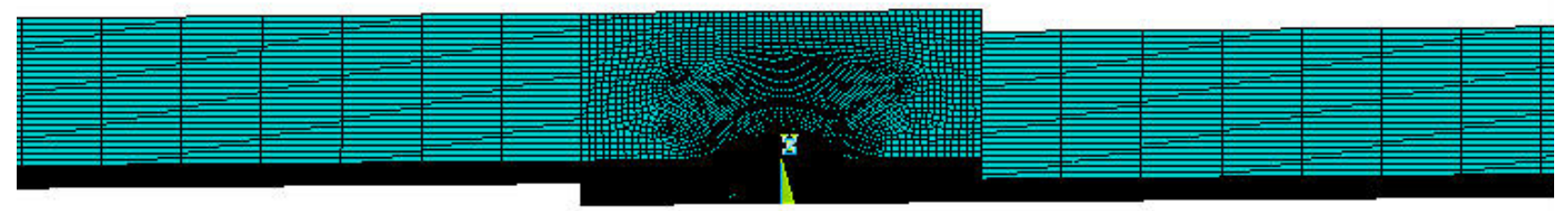

(a) FEM model 


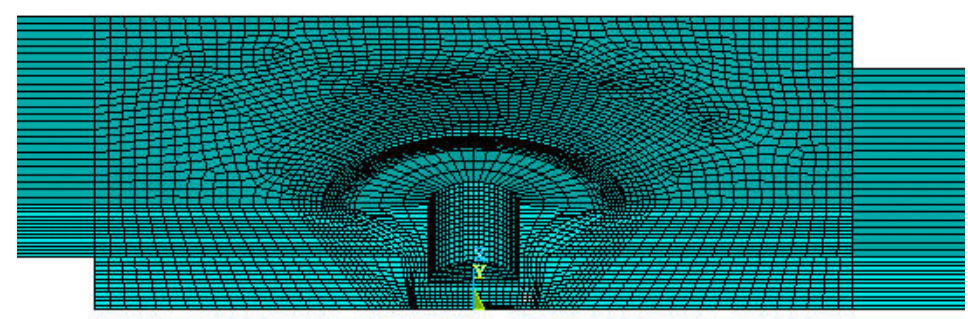

(b) partial enlarged details

Fig. 2. Simulation model of FSSW joints

The sheet thickness is chosen as $2.0 \mathrm{~mm}$, with $3.0 \mathrm{~mm}$ of tip diameter, and $10 \mathrm{~mm}$ of shoulder diameter. Contact elements are defined between upper sheet and lower sheet to prevent the phenomenon of the plate penetration during simulation analysis. In order to improve the precise of simulation, elements surrounding the SZ, TMAZ and HAZ are smart meshed. Mechanical properties of base material 6061-T6 are shown in table 1 .

Table 1. Mechanical properties of aluminum alloy

\begin{tabular}{ccccc}
\hline Material & $\mathrm{E}(\mathrm{MPa})$ & $v$ & $\sigma_{\mathrm{y}}(\mathrm{MPa})$ & $\sigma_{\text {uts }}(\mathrm{MPa})$ \\
\hline $6061-\mathrm{T} 6$ & $6.9 \mathrm{E} 10$ & 0.33 & 275 & 310 \\
\hline
\end{tabular}

\section{Simulation Results}

Simulation analysis of the mechanical properties of the aluminum alloy friction stir spot welds is shown in Figure 3. Stress distribution and welds deformation with tensile shear load is investigated. It can be seen that stress concentration occurs in the welds interface at the beginning of the simulation, and the plastic strain trend is evaluated in the zone near the weld. With the increase of tensile shear load, the stress is improved and the stress concentration area is transferred to the plate surface gradually. High stress phenomenon is also found in the surrounding area of the SZ. However, because of good thermal enhancement in SZ and high decrease in the material properties in HAZ, crack firstly produced in the HAZ, then extended along the stirring zone direction, to finial fracture.

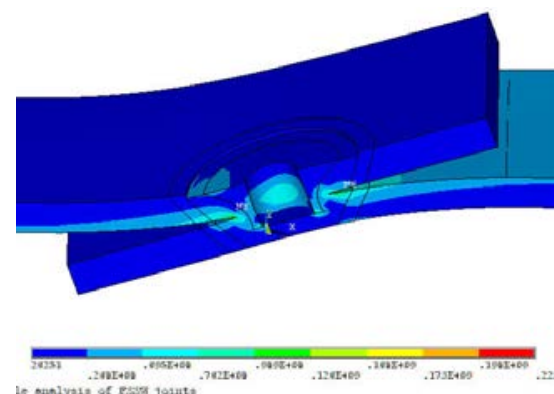

(a) $\mathrm{t}=0.0133 \mathrm{~s}$

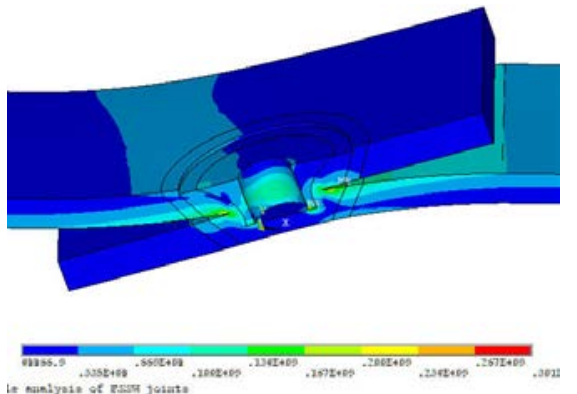

(b) $\mathrm{t}=0.0266 \mathrm{~s}$

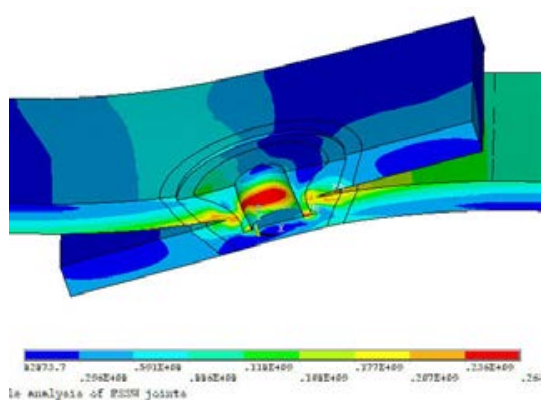

(c) $\mathrm{t}=0.0467 \mathrm{~s}$

Fig.3. Stress distributions

\section{Conclusion}

In this work a structural analysis of mechanical properties of FSSW joint is performed, based on the microstructure characteristics. Numerical simulation model of FSSW joint with tensile shear load is conducted, and stress distribution is obtained. Consequently, the failure mechanism is revealed through the numerical results, which can provide guidance for improving the quality of FSSW joints.

\section{Acknowledgement}

In this paper, the research was sponsored by the Natural Science Foundation of Shanghai (Project No. 13ZR1417400) and the Innovation Program of Shanghai Municipal Education Commission (Project No. 13YZ137). 


\section{References}

[1] Buffa G., Fratini L., Piacentini M., On the influence of tool path in friction stir spot welding of aluminum alloys [J], Journal of Materials Processing Technology, 2008, 208(1/3):309-317.

[2] Badarinarayan H., Yang Q., and Hunt F., Effect of Pin Geometry on Static Strength of Friction Stir Spot Welds[C]. SAE Paper, 2008, No. 2008-01-0147-0152.

[3] Merzoug M., Mazari M., Berrahal L., Imad A., Parametric studies of the process of friction spot stir welding of aluminium 6060-T5 alloys[J], Materials and Design, 2010, 31:3023-3028.

[4] Sato Y. S., Shiota A., Kokawa H., etc, Effect of interfacial microstructure on lap shear strength of friction stir spot weld of aluminium alloy to magnesium alloy [J], Science and Technology of Welding and Joining, 2010, 15(4):319-324.

[5] K. Dongun, B. Harsha, R. Ill, H. K. Ji, K. Chongmin, O. Kazutaka, Numerical simulation of friction stir spot welding process for aluminum alloys [J], Metals and Materials International, 2010, 16(2): 323-332.

[6] S. Hirasawa, H. Badarinarayan, K. Okamoto, T. Tomimura, Analysis of Temperature and Plastic Flow during Friction Stir Spot Welding Using Particle Method [J], Journal of Thermal Science and Technology, 2009, 4(2):260-271.

[7] Zhou M, Zhang $\mathrm{H}$ and Hu S J. Relationship between quality and attributes of spot welds [J]. Welding Journal, 2003, 82(4): 72-77. 